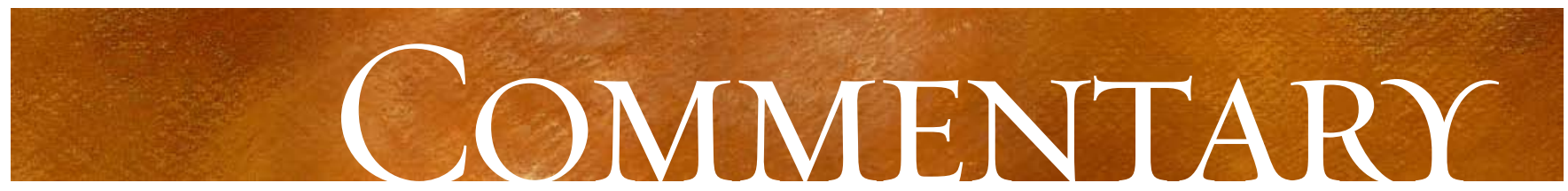

\title{
Public health implications of MRSA in Canada
}

\author{
Upton D. Allen
}

Published at www.cmaj.ca on June 27, 2006.

$\infty$

See related article page $\mathrm{I} 49$

$\mathrm{M}$ ethicillin-resistant Staphylococcus aureus (MRSA) has become established in acute and long-term health facilities worldwide. Currently, 2 main categories are recognized: hospital-associated (HA-MRSA) and community-associated MRSA (CA-MRSA). Infections caused by CA-MRSA begin in the community in people who lack known HA-MRSA risk factors, including recent hospital contact, surgery, residence in a long-term care facility, dialysis or presence of invasive medical devices. ${ }^{1}$ CA-MRSA strains have emerged in community settings worldwide. ${ }^{2-4}$ Cases are most frequently described within reasonably well-defined populations, such as among children, military recruits, incarcerated people, men who have sex with men, sports teams and native populations, among others. ${ }^{5}$ In these groups, the spread of infection is likely facilitated by suboptimal hygiene, crowding, frequent skin-to-skin contact and the sharing of personal items that may become contaminated.

The 2 categories of MRSA have distinct characteristics. CA-MRSA strains exhibit resistance to fewer classes of antimicrobials than does HA-MRSA. CA-MRSA strains also exhibit specific virulence factors, notably the Panton-Valentine leukocidin genes, ${ }^{6}$ which produce cytotoxins capable of inducing severe tissue necrosis and leukocyte destruction. The CA-MRSA strains currently circulating can be distinguished with molecular typing methods, such as pulsed-field gel electrophoresis and multilocus sequence typing. Pulsed-field typing has indicated that among the more common lineages of MRSA that have been described, USAroo and USA200 are associated with HA-MRSA, ${ }^{7}$ whereas the USA400 and USA 300 clones have been associated with most of the outbreaks of CA-MRSA in the United States. ${ }^{8,9}$ The USA30o clones are clearly of relevance to Canada, as indicated by Gilbert and colleagues' report in this issue of CMAJ. ${ }^{10}$

The distinction between the 2 types of MRSA infections will become less clear as CA strains become disseminated within health care institutions by nosocomial transmission and the HA strains are carried out into the community. Thus, people within community or health care settings could become infected with MRSA strains of either category. Current reporting and surveillance mechanisms in Canada do not always permit a clear distinction between the 2 categories of MRSA.

Although the overall burden of MRSA infection is current- ly less in Canada than in some North American regions, such patterns can change, as illustrated by the experience in Texas. At the Texas Children's Hospital (TCH), the percentage of strains of MRSA that were CA have increased each year. Methicillin-sensitive strains of $S$. aureus currently account for less than one-quarter of cases of community isolates of $S$. aureus there. ${ }^{11}$ Moreover, many of the MRSA infections result from the community onset of HA-MRSA. ${ }^{12}$ Thus, for that particular region, "the horses may have already left the starting gate" as far as the likelihood of control measures to be effective is concerned.

Recently, the US Centers for Disease Control and Prevention (CDC) released strategies for case management of MRSA in community settings, particularly of skin and soft-tissue infections. ${ }^{5}$ In Canada, it is not yet too late to attempt to control the dissemination of MRSA in the community. Educational efforts have been proposed that target communities that have experienced greater community carriage rates of MRSA (e.g., First Nations communities). ${ }^{13}$

\section{High-risk populations could act as vectors for the US3OO strain of MRSA.}

Gilbert and colleagues ${ }^{10}$ describe the results of an investigation of an outbreak of CA-MRSA in a marginalized population in the Calgary Health Region (CHR). Their report is characterized by several features important to public health. First, the outbreak was associated with the USA30o strain of MRSA. This is the first reported Canadian outbreak caused by this strain, although strains of USA40o isolated from skin and soft-tissue infections in east-central Saskatchewan have been documented. ${ }^{14}$ Second, the people at highest risk of infection were those with histories of illicit drug use, homelessness or recent incarceration. They could therefore act as vectors for this strain of MRSA, to spread it to other urban areas, health care facilities, prisons and shelters. This concern illustrates the importance of the report by Gilbert's group. Third, the ill- 
nesses were relatively severe: a considerable proportion of the people infected required outpatient intravenous antibiotic therapy. The authors have suggested several hypotheses to explain the spread of the USA 300 strain within the marginalized population, including close contact with self-treated draining boils, the sharing of drug paraphernalia and the congregation of colonized residents of crack houses, shelters for homeless people, detoxication centres and correctional facilities. The reasons for the spread of this strain are multifactorial and constitute an excellent example of how CA-MRSA strains can become disseminated in a community of people with characteristics that make control measures difficult to implement, and lead to amplification of the prevalence and transmission of these strains.

The occurrence of infections with MRSA in community settings has important implications for public health and the approach to case management of $S$. aureus infections. A pivotal consideration is the appropriate use of surveillance and reporting procedures to identify cases and early trends in order to guide the public health response. This may require a more structured and regulated approach to reporting and surveillance at the provincial as well as the national level.

Although CA-MRSA has been associated mostly with skin and soft-tissue infections, severe invasive infections can also occur. ${ }^{15}$ Given that the $S$. aureus pathogen is common, the advent of strains that are more virulent (CA-MRSA) or resistant to antibiotics (HA-MRSA) may herald the onset of more severe forms of common staphylococcal diseases (e.g., skin infections, pneumonias and osteomyelitis). Our approach to the management of these infections would need to change, with emphasis on early recognition and the need to target antibiotic therapy appropriately, with use of risk stratification strategies, culture results and susceptibility testing, as appropriate.

Data are lacking on the most effective strategies to control the spread of MRSA in community settings. However, certain approaches should be optimized through education, including attention to basic hygiene and wound care. In recent CDC recommendations, patient education was noted to be crucial in the management of people with MRSA-related skin and soft-tissue infections. ${ }^{5}$ If they cannot maintain adequate hygiene and wound care, it may also be necessary to impose restrictions on their activities (e.g., exclusion from daycare or athletic practice). Multifaceted control measures will need to be tailored to specific high-risk groups, such as those described by Gilbert and colleagues.

Collaborative efforts in public health should include veterinary facilities, as evidenced by a recent report indicating that MRSA transfer among some animals, such as horses, is of concern. ${ }^{16}$ The possibility of transmission between animals and humans has also been raised. ${ }^{17}$

It is not too late to attempt to control MRSA in Canada. The "hot zones" of MRSA in Canada need to be further defined. Are there others similar to those described in the
Gilbert report $?^{10}$ Research is needed to further define the epidemiologic and microbiologic characteristics of MRSA in community settings. Studies are also required to optimize the diagnosis, treatment and prevention of CA-MRSA. To this end, given that MRSA does not respect provincial, territorial or other jurisdictional boundaries, national collaborative efforts are required.

This article has been peer reviewed.

Upton Allen is from the Division of Infectious Diseases, Department of Pediatrics, The Hospital for Sick Children and University of Toronto, Toronto, Ont.

Competing interests: None declared.

\section{REFERENCES}

I. Fridkin SK, Hageman JC, Morrison M, et al. Methicillin-resistant Staphylococcus aureus disease in three communities. N Engl J Med 2005;352:1436-44.

2. Udo EE, Pearman JW, Grubb WB. Genetic analysis of community isolates of methicillin-resistant Staphylococcus aureus in Western Australia. J Hosp Infect I993;25:97-I08.

3. Taylor G, Kirkland T, Kowalewska-Grochowska K, et al. A multistrain cluster of methicillin-resistant Staphylococcus aureus based in a Native community. Can J Infect Dis I990; I:I2I-6.

4. Vandenesch F, Naimi T, Enright MC, et al. Community-acquired methicillinresistant Staphylococcus aureus carrying Panton-Valentine leukocidin genes: worldwide emergence. Emerg Infect Dis 2003;9:978-84.

5. Gorwitz RJ, Jernigan DB, Powers JH, Jernigan JA, and participants in the CDC Convened Experts' Meeting on Management of MRSA in the Community. Strategies for clinical management of MRSA in the community: summary of an experts' meeting convened by the Centers for Disease Control and Prevention. 2006. Available: www.cdc.gov/ncidod/dhqp/ar_mrsa_ca.html (accessed 2006 May 30).

6. Lina G, Piemont Y, Godail-Gamot F, et al. Involvement of Panton-Valentine leukocidin-producing Staphylococcus aureus in primary skin infections and pneumonia. Clin Infect Dis I999;29:1128-32.

7. McDougal LK, Steward CD. GE, Chaitram JM, McAllister SK, Tenover FC. Pulsedfield gel electrophoresis typing of oxacillin-reisistant Staphylococcus aureus isolates from the United States: establishing a national database. J Clin Microbiol 2003;4I:5113-20.

8. Chambers HF. Community-associated MRSA - resistance and virulence converge. N Engl J Med 2005;352:1485-7.

9. Buckingham SC, McDougal LK, Cathey LD, et al. Emergence of communityassociated methicillin-resistant Staphylococcus aureus at a Memphis, Tennessee children's hospital. Pediatr Infect Dis J 2004;23:619-24.

Io. Gilbert M, MacDonald J, Gregson D, et al. Outbreak in Alberta of communityacquired (USA30o) methicillin-resistant Staphylococcus aureus in people with a history of drug use, homelessness or incarceration. CMAJ 2006;175(2):I49-54.

II. Kaplan SL, Hultén KG, Gonzalez et al. Three-year surveillance of community-acquired Staphylococcus aureus infections in children. Clin Infect Dis 2005;40:1785-9I.

I2. Hultén KG, Kaplan SL, Gonzalez BE, et al. Three-year surveillance of community onset health care-associated Staphylococcus aureus infections in children. Pediatr Infect Dis J 2006;25:349-53.

I3. First Nations and Inuit Health Committee, Canadian Pediatric Society. Methicillinresistant Staphylococcus aureus in First Nations communities in Canada. Paediatr Child Health 2005; I0:557-9.

I4. Mulvey M, MacDougall L, Cholin B, et al. Community-associated methicillinresistant Staphylococcus aureus, Canada. Emerg Infect Dis 2005;11:844-50.

15. Centers for Disease Control and Prevention. Four pediatric deaths from communityacquired methicillin-resistant Staphylococcus aureus - Minnesota and North Dakota, I997-I999. MMWR I999;48:707-Io.

I6. Weese JS, Rousseau J, Willey BM, et al. Methicillin-resistant Staphylococcus aureus in horses at a veterinary teaching hospital: frequency, characterization, and association with clinical diseases. $J$ Vet Intern Med 2006;20:182-6.

17. Weese JS, Dick H, Willey BM, McGeer A, et al. Suspected transmission of methicillinresistant Staphylococcus aureus between domestic pets and humans in veterinary clinics and in the household. Vet Microbiol 2006;II5:I48-55. Epub 2006 Feb 7

Correspondence to: Dr. Upton Allen, 555 University Ave., Toronto ON M5G IX8; fax 4I6 813-8404; upton.allen@sickkids.ca 